\title{
Chapter 8 \\ Molecular Subtypes and Driver Mutations in Latinos with Gastric Cancer: \\ Implications for Etiological and Translational Research
}

\author{
Luis G. Carvajal-Carmona
}

\section{Gastric Cancer Is a Common Malignancy with Poor Outcomes}

Worldwide, gastric cancer (GC) is the third leading cause of cancer mortality [1]. Each year $\sim 1$ million new gastric cancer (GC) cases are diagnosed and >720,000 patients die of GC $[2,3]$. GC prognosis is dismal because early-stage tumors, where survival is high, are clinically silent and difficult to detect. Most GCs are detected in late stages and have 5-year survival rates $<10 \%[2,4,5]$. To improve GC outcomes, major limitations need to be addressed. First, new prevention and early detection tools must be developed, including the identification of susceptibility genes that allow the identification of high-risk individuals. Until recently, E-cadherin (also known as $\mathrm{CDH1}$ ) was the only known GC gene; it accounts for $40 \%$ of cases with hereditary diffuse GC (HDGC) syndrome and a very small fraction of non-HDGC cases $[2,6,7]$. We recently identified a second familial GC form, involving germline mutations in recombination DNA repair genes, which account for $2-6 \%$ of all cases $[1,8,9]$. Even though this recent gene discovery represents an important advance, few individuals currently benefit from genetic-guided prevention. Another major limitation is the need to develop effective therapies to improve GC outcomes. The Cancer Genome Atlas (TCGA) study found that $>70 \%$ of all GCs have mutations that can be targeted with existing drugs [10]. Despite this large fraction of "druggable" mutations, only two GC-targeted therapies have been approved by the

\footnotetext{
L. G. Carvajal-Carmona $(\bowtie)$

Genome Center, University of California Davis, Davis, CA, USA

Department of Biochemistry and Molecular Medicine, School of Medicine, University of California Davis, Sacramento, CA, USA

University of California Davis Comprehensive Cancer Center, University of California Davis, Sacramento, CA, USA

e-mail: lgcarvajal@ucdavis.edu
} 
Table 8.1 Disparities in gastric cancer incidence and mortality in Latinos and in non-Latino whites (NLW ) (data from the American Cancer Society report [15])

\begin{tabular}{l|c|l|l|l|l|l}
\hline & \multicolumn{3}{|l|}{ Incidence per 100,000 individuals } & \multicolumn{3}{l}{ Mortality per 100,000 individuals } \\
\cline { 2 - 7 } & Latinos & NLW & Disparity ratio & Latinos & NLW & Disparity ratio \\
\hline Men & 13.5 & 7.8 & 1.7 & 7.2 & 3.6 & 2.0 \\
\hline Women & 7.8 & 3.5 & 2.2 & 4.2 & 1.8 & 2.3 \\
\hline
\end{tabular}

Food and Drug Administration (FDA) [11, 12]. Hence, major advances in etiological and translational research are needed to improve GC outcomes through prevention, early detection, and better treatments.

\section{Gastric Cancer in Latinos}

GC exemplifies a malignancy with strong disparities in incidence, mortality, and survival that disproportionately affects Latinos, the largest and youngest US minority population [13-16]. Table 8.1 shows incidence and mortality rates (per 100,000 people) in NLW, Latinos, and their associated disparities [15]. Latinos are between 1.7- and 2.2-fold more likely than NHWs to be diagnosed with GC and between 2.0- and 2.3-fold more likely to die when diagnosed. These disparities are among the highest in the country and are not fully accounted for by differences in the prevalence of known risk factors or access to healthcare. Addressing these disparities should be a priority in etiological and outcome research in the country.

\section{Genomic and Genetic Research Disparities}

Relative to NLW, very limited GC genetic or genomic research has been carried out in Latino populations. All published GC genome-wide association studies (GWAS) have been carried out in Asians [17-20] or NLW [21], and no data are available on the risk that GWAS variants confer in Latino populations. Furthermore, all gastric tumor whole exome or whole genome sequencing studies carried out to date have only involved either Asian [22-28] or, as in the TCGA, predominantly NLW [10]. Table 8.2 shows the ethnic/racial composition of the TCGA patients, where Latinos represent only $1 \%$ of the participants. It is unfortunate that the minority population with the highest GC burden in the country was not fully represented in such an important study. To my knowledge, there is no published Latino data on the prevalence of the four TCGA molecular subtypes (Epstein-Barr virus associated, EBV; microsatellite instable, MSI; genomically stable, GS; and chromosomally instable, CIN) or of the mutation prevalence of the TCGA driver genes. Investigating Latino GC genomics is needed, because many somatic alterations are druggable and the TCGA new molecular subtypes show important differences in prognosis and response to therapy [29]. Having such information on population-specific molecular 
Table 8.2 The racial/ethnic composition of the GC patients included in TCGA [10]

Table 8.3 Epidemiological profiles of gastric cancers in Latinos and NLWs from California (2010-2014) (data from [31])

\begin{tabular}{l|l}
\hline Race/ethnicity & $\begin{array}{l}\text { Fraction of patients } \\
(n=295)(\%)\end{array}$ \\
\hline Non- Latino whites & 63 \\
\hline Asians & 20 \\
\hline Latinos & 1 \\
\hline Other & 14 \\
\hline
\end{tabular}

\begin{tabular}{|c|c|c|}
\hline & $\begin{array}{l}\text { Latinos } \\
(n=3879)\end{array}$ & $\begin{array}{l}\text { NLW } \\
(n=4612)\end{array}$ \\
\hline \multicolumn{3}{|l|}{ Sex } \\
\hline Men & $2166(56 \%)$ & $3048(66 \%)$ \\
\hline Women & $1713(44 \%)$ & $1564(34 \%)$ \\
\hline \multicolumn{3}{|l|}{ Age } \\
\hline Early onset ( $\leq 50$ years) & $880(23 \%)$ & $363(8 \%)$ \\
\hline Late onset (>50 years) & $2999(77 \%)$ & $4249(92 \%)$ \\
\hline \multicolumn{3}{|l|}{ Socioeconomic status } \\
\hline Lowest & $1285(37 \%)$ & $435(14 \%)$ \\
\hline Medium/high & $2145(63 \%)$ & $2736(86 \%)$ \\
\hline \multicolumn{3}{|l|}{ Histology } \\
\hline Intestinal & $1929(62 \%)$ & $2739(77 \%)$ \\
\hline Diffuse & $1187(38 \%)$ & $828(23 \%)$ \\
\hline \multicolumn{3}{|l|}{ Stage } \\
\hline Localized & $887(23 \%)$ & $1282(38 \%)$ \\
\hline Regional/remote & $2580(77 \%)$ & $2895(62 \%)$ \\
\hline
\end{tabular}

profiles will empower studies aimed at improving GC outcomes in this minority population. Furthermore, Latino-focused genomic research efforts will help avoid widening the pervasive gap in cancer disparities [30].

\section{The Unique Epidemiology of Gastric Cancer in Latinos}

Table 8.3 presents GC incidence and mortality data for Latinos and NLWs from California. These data are interesting because GC profiles show important population differences. Latinos have a higher fraction of women with GC (44\% vs. $34 \%$ in NLWs) and more GC patients with lower socioeconomic status (37\% vs. $14 \%$ in NLWs). Furthermore, Latinos are more often diagnosed with GC by age 50 years ( $23 \%$ vs. $8 \%$ in NLWs), diffuse tumors (38\% vs. $23 \%$ in NLWs), and regional and distant metastasis $(77 \%$ vs. $62 \%$ in NLWs). These data therefore suggest that the epidemiology of GC in Latinos is unique and highlights the need for research that uncovers etiological differences between Latinos and other populations. 
Table 8.4 Mutation frequency data of known gastric cancer driver genes in Latinos and TCGA (Luis Carvajal-Carmona laboratory, unpublished)

\begin{tabular}{l|l|l}
\hline \multirow{2}{*}{ Gene } & \multicolumn{3}{|l}{ Mutation frequency } \\
\cline { 2 - 3 } TCGA $(n=295)$ & Latinos $(n=30)$ \\
\hline ARID1A & 0.14 & 0.00 \\
\hline PIK3CA & 0.12 & 0.04 \\
\hline CDH1 & 0.11 & 0.04 \\
\hline
\end{tabular}

\section{Molecular GC Profiles in Latinos Are Unique}

The new TCGA GC molecular classification is important, because some of these subtypes have been associated with the prognosis or with response to therapy. Specifically, GC patients with EBV subtype tumors have excellent prognoses, while those with the GS subtype have poorer outcomes [29]. A recent study by Sohn et al. [29] also showed that patients with GS tumors do not benefit from chemotherapy, highlighting the need for research aiming at developing effective therapies for this subtype. To establish the prevalence of GC molecular subtypes in Latinos, our group recently carried out a pilot study of targeted sequencing in 30 tumors from Latino patients. Relative to TCGA, our unpublished study found that Latinos have a lower prevalence of CIN (33\% vs. 49\%) tumors and a higher prevalence of the GS (39\% vs. 19\%) subtype. We also found that the prevalence of mutations in driver genes is very different in Latinos (see Table 8.4 for some examples). These unpublished data suggest that the molecular profiles of GCs in Latinos are unique and highlight the need for larger and more comprehensive tumor genomic studies in the population.

\section{Conclusions}

Latinos have the highest GC burden in the United States. Published data and ongoing research suggest that the epidemiology of GC in Latinos is unique. It is now critically important to carry out studies that help us understand the etiology of GC in this minority population and that further characterize genetic and genomic patterns in GC patients of Latino ancestry. Furthermore, the unique molecular patterns in Latino GCs warrants future preclinical and translation studies in driver genes and molecular subtypes that are more prevalent in this minority population.

Acknowledgments I am indebted to all my collaborators and to the participants in our studies. I am grateful for research funding from the University of California, Davis (School of Medicine Dean's Fellowship in Precision Health Equity; Office of the Provost supported Latino Cancer Health Equity Initiative); COLCIENCIAS (Project Evaluacion de exoma de pacientes Colombianos con cancer gastrico y de genoma de Helicobacter pylori, code 110565843382, contract 204-2015) and from the National Cancer Institute (grants R01CA223978, R21CA199631, U54CA233306, and P30CA093373) and from the National Institute of Environmental Health Sciences (grant P30ES023513) of the National Institutes of Health. The content of this chapter is solely the responsibility of the author and does necessarily represent the official views of the National Institutes of Health. 


\section{References}

1. Lott PC, Carvajal-Carmona LG. Resolving gastric cancer aetiology: an update in genetic predisposition. Lancet Gastroenterol Hepatol. 2018;3(12):874-83.

2. de Martel C, Forman D, Plummer M. Gastric cancer: epidemiology and risk factors. Gastroenterol Clin N Am. 2013;42(2):219-40.

3. Ferlay J, Soerjomataram I, Dikshit R, Eser S, Mathers C, Rebelo M, et al. Cancer incidence and mortality worldwide: sources, methods and major patterns in GLOBOCAN 2012. Int J Cancer. 2015;136(5):E359-86.

4. Guggenheim DE, Shah MA. Gastric cancer epidemiology and risk factors. J Surg Oncol. 2013;107(3):230-6.

5. Haile RW, John EM, Levine AJ, Cortessis VK, Unger JB, Gonzales M, et al. A review of cancer in U.S. Hispanic populations. Cancer Prev Res (Phila). 2012;5(2):150-63.

6. Chun N, Ford JM. Genetic testing by cancer site: stomach. Cancer J. 2012;18(4):355-63.

7. Guilford P, Hopkins J, Harraway J, McLeod M, McLeod N, Harawira P, et al. E-cadherin germline mutations in familial gastric cancer. Nature. 1998;392(6674):402-5.

8. Carvajal-Carmona LG. PALB2 as a familial gastric cancer gene: is the wait over? Lancet Gastroenterol Hepatol. 2018;3(7):451-2.

9. Sahasrabudhe R, Lott P, Bohorquez M, Toal T, Estrada AP, Suarez JJ, et al. Germline mutations in PALB2, BRCA1, and RAD51C, which regulate DNA recombination repair, in patients with gastric cancer. Gastroenterology. 2017;152(5):983-6. e6

10. Cancer Genome Atlas Research Network. Comprehensive molecular characterization of gastric adenocarcinoma. Nature. 2014;513(7517):202-9.

11. Bang YJ, Van Cutsem E, Feyereislova A, Chung HC, Shen L, Sawaki A, et al. Trastuzumab in combination with chemotherapy versus chemotherapy alone for treatment of HER2-positive advanced gastric or gastro-oesophageal junction cancer (ToGA): a phase 3, open-label, randomised controlled trial. Lancet. 2010;376(9742):687-97.

12. Fuchs CS, Tomasek J, Yong CJ, Dumitru F, Passalacqua R, Goswami C, et al. Ramucirumab monotherapy for previously treated advanced gastric or gastro-oesophageal junction adenocarcinoma (REGARD): an international, randomised, multicentre, placebo-controlled, phase 3 trial. Lancet. 2014;383(9911):31-9.

13. González Burchard E, Borrell LN, Choudhry S, Naqvi M, Tsai H-J, Rodriguez-Santana JR, Chapela R, Rogers SD, Mei R, Rodriguez-Cintron W, Arena JF, Kittles R, Perez-Stable EJ, Ziv E, Risch N. Latino Populations: A Unique Opportunity for the Study of Race, Genetics, and Social Environment in Epidemiological Research. American Journal of Public Health. 2005; 95(12):2161-8.

14. Siegel R, Ward E, Brawley O, Jemal A. Cancer statistics, 2011: the impact of eliminating socioeconomic and racial disparities on premature cancer deaths. CA Cancer J Clin. 2011;61(4):212-36.

15. Siegel RL, Fedewa SA, Miller KD, Goding-Sauer A, Pinheiro PS, Martinez-Tyson D, et al. Cancer statistics for Hispanics/Latinos, 2015. CA Cancer J Clin. 2015;65(6):457-80.

16. Siegel RL, Miller KD, Jemal A. Cancer statistics, 2017. CA Cancer J Clin. 2017;67(1):7-30.

17. Abnet CC, Freedman ND, Hu N, Wang Z, Yu K, Shu XO, et al. A shared susceptibility locus in PLCE1 at 10q23 for gastric adenocarcinoma and esophageal squamous cell carcinoma. Nat Genet. 2010;42(9):764-7.

18. Shi Y, Hu Z, Wu C, Dai J, Li H, Dong J, et al. A genome-wide association study identifies new susceptibility loci for non-cardia gastric cancer at 3q13.31 and 5p13.1. Nat Genet. 2011;43(12):1215-8.

19. Wang Z, Dai J, Hu N, Miao X, Abnet CC, Yang M, et al. Identification of new susceptibility loci for gastric non-cardia adenocarcinoma: pooled results from two Chinese genome-wide association studies. Gut. 2017;66(4):581-7.

20. Hu N, Wang Z, Song X, Wei L, Kim BS, Freedman ND, et al. Genome-wide association study of gastric adenocarcinoma in Asia: a comparison of associations between cardia and noncardia tumours. Gut. 2016;65(10):1611-8. 
21. Helgason H, Rafnar T, Olafsdottir HS, Jonasson JG, Sigurdsson A, Stacey SN, et al. Loss-offunction variants in ATM confer risk of gastric cancer. Nat Genet. 2015;47(8):906-10.

22. Rokutan H, Hosoda F, Hama N, Nakamura H, Totoki Y, Furukawa E, et al. Comprehensive mutation profiling of mucinous gastric carcinoma. J Pathol. 2016;240(2):137-48.

23. Kim TM, Jung SH, Kim MS, Baek IP, Park SW, Lee SH, et al. The mutational burdens and evolutionary ages of early gastric cancers are comparable to those of advanced gastric cancers. J Pathol. 2014;234(3):365-74.

24. Chen K, Yang D, Li X, Sun B, Song F, Cao W, et al. Mutational landscape of gastric adenocarcinoma in Chinese: implications for prognosis and therapy. Proc Natl Acad Sci U S A. 2015;112(4):1107-12.

25. Kakiuchi M, Nishizawa T, Ueda H, Gotoh K, Tanaka A, Hayashi A, et al. Recurrent gain-offunction mutations of RHOA in diffuse-type gastric carcinoma. Nat Genet. 2014;46(6):583-7.

26. Liu J, McCleland M, Stawiski EW, Gnad F, Mayba O, Haverty PM, et al. Integrated exome and transcriptome sequencing reveals ZAK isoform usage in gastric cancer. Nat Commun. 2014;5:3830.

27. Zang ZJ, Cutcutache I, Poon SL, Zhang SL, McPherson JR, Tao J, et al. Exome sequencing of gastric adenocarcinoma identifies recurrent somatic mutations in cell adhesion and chromatin remodeling genes. Nat Genet. 2012;44(5):570-4.

28. Wang K, Yuen ST, Xu J, Lee SP, Yan HH, Shi ST, et al. Whole-genome sequencing and comprehensive molecular profiling identify new driver mutations in gastric cancer. Nat Genet. 2014;46(6):573-82.

29. Sohn BH, Hwang JE, Jang HJ, Lee HS, Oh SC, Shim JJ, et al. Clinical significance of four molecular subtypes of gastric cancer identified by the Cancer Genome Atlas project. Clin Cancer Res. 2017; https://doi.org/10.1158/1078-0432.CCR-16-2211.

30. Spratt DE, Chan T, Waldron L, Speers C, Feng FY, Ogunwobi OO, et al. Racial/ethnic disparities in genomic sequencing. JAMA Oncol. 2016;2(8):1070-4.

31. Klapheke AK, Carvajal Carmona LG, Cress R. Racial/ethnic differences in survival among gastric cancer patients in California. Cancer Causes Control. 2019;30(7):687-96.

Open Access This chapter is licensed under the terms of the Creative Commons AttributionNonCommercial 4.0 International License (http://creativecommons.org/licenses/by-nc/4.0/), which permits any noncommercial use, sharing, adaptation, distribution and reproduction in any medium or format, as long as you give appropriate credit to the original author(s) and the source, provide a link to the Creative Commons license and indicate if changes were made.

The images or other third party material in this chapter are included in the chapter's Creative Commons license, unless indicated otherwise in a credit line to the material. If material is not included in the chapter's Creative Commons license and your intended use is not permitted by statutory regulation or exceeds the permitted use, you will need to obtain permission directly from the copyright holder. 